\title{
Kisah Dramatisasi Saudara-Saudara Nabi Yusuf Dalam Al-Qur'An Dengan Pendekatan Teori Konspirasi
}

\author{
Fredi Suhendra \\ Universitas Islam Negeri Raden Fatah Palembang \\ fredisuhendra@45.com
}

\begin{abstract}
Abstrak
Artikel ini membahas tentang kisah dramtisasi saudara-saudara Nabi Yusuf dalam al-Qur'an. Dengan menggunakan pendekatan teori konspirasi, artikel ini menghasilkan temuan bahwa praktik dramatisasi konspirasi yang diterapkan saudara-saudara Nabi Yusuf as merupakan proses dramatisasi alur kerja konspirasi yang dipraktikkan oleh saudara-saudara Nabi Yusuf as sangat terstruktur. Mereka memulainya dengan berdiskusi, bermufakat menyusun rekonstruksi strategi secara berkelompok dan ter-organisir, kemudian melakukan koorporasi kepada ayahnya Ya qub as melalui pendekatan persuasif, berkamuflase sehingga menciptakan daya tarik emosi, hingga klimaksnya Nabi Yusuf as berada di dalam sumur. Di mana yang mengusulkan agar Yusuf as dimasukkan ke dalam sumur yakni, Ruben merupakan saudara tirinya sendiri.

Kata kunci: Al-Qur'an, dramatisasi, kisah saudara Nabi Yusuf, konspirasi
\end{abstract}

\begin{abstract}
This article discusses the story of the dramatization of the Prophet Yusuf's brothers in the Qur'an. By using a conspiracy theory approach, this article finds that the practice of dramatizing the conspiracy applied by the brothers of Prophet Yusuf as is a highly structured process of dramatizing the conspiracy workflow practiced by the brothers of Prophet Yusuf. They started by discussing, agreeing to formulate a strategic reconstruction in groups and in an organized manner, then cooperated with his father Ya'qub as through a persuasive approach, camouflaged so as to create emotional attraction, until the climax of Prophet Yusuf as being in a well. The one who suggested that Yusuf (as) be put into the well, namely, Reuben was his own half-brother.

Keywords: Al-Qur'an, dramatization, the story of the Prophet Yusuf's brother, conspiracy
\end{abstract}




\section{PENDAHULUAN}

Kisah-kisah di dalam Al-Qur`an mendeskripsikan terdapat tanda-tanda kekuasaan Allah SWT bagi orang yang bertanya, sedikitnya disebutkan ada 29 surah. ${ }^{1}$ Merujuk pada hal tersebut, Manna' Al-Qathhan berpandangan bahwa tujuan kisah dalam Al-Qur'an menjadi pelajaran (ibrah) bagi umat manusia. Berbagai macam yang diceritakan oleh Al-Qur`an,. dari sekian banyak qashash di antaranya bercerita umat, tokoh peristiwa masa lalu, dan para nabi dan rasul. ${ }^{2}$

Salah satunya mengisahkan tentang Nabi Yusuf as. Al-Qur`an sendiri menggambarkan rekonstruksi secara utuh satu kesatuan per-episode dalam surah Yusuf, dari ia bermimpi melihat sebelas bintang, mendapatkan konspirasi dari saudara-saudaranya, hingga klimaksnya menjadi seorang pembesar di daratan Mesir. perjalanannya begitu banyak cobaan dan ujian dari Allah SWT. ${ }^{3}$

Konpirasi tersebut dibuktikan dengan pernyataan Al-Qur`an sendiri yang dibuat oleh saudara-saudaranya, disebutkan dalam beberapa kitab tafsir. ${ }^{4}$ Surah Yusuf: 9-10:

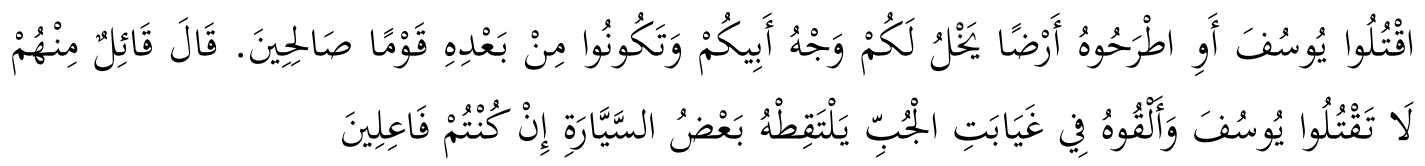

"Bunuhlah Yusuf atau buanglah Dia kesuatu daerah (yang tak dikenal) supaya perhatian ayahmu tertumpah kepadamu saja, dan sesudah itu hendaklah kamu menjadi orang-orang yang baik. Seorang diantara mereka berkata: "Janganlah kamu bunuh Yusuf, tetapi masukkanlah Dia ke dasar sumur supaya Dia dipungut oleh beberapa orang musafir, jika kamu hendak berbuat."

Praktik konspirasi tersebut berlanjut pada masa Rasulullah SAW, orangorang kafir Quraisy bermusyawarah di Mekkah membuat propaganda dengan memikirkan tipu daya yang hendak membunuh Nabi Muhammad SAW, sebagian lagi dari mereka bermufakat janganlah dibunuh, akan tetapi usir dan ikat saja di pelataran kota Mekkah. Dari Muqsim Maula Ibnu `Abbas, ia diberitahu berkenaan dengan firman Allah SWT وَاذْ يَكْكُرُ بِكَ (Dan ingatlah ketika orang-orang kafir melakukan

${ }^{1}$ Di antaranya surah Al-A`raf, Yunus, Hud, Yusuf, Ibrahim, Al-Hijr dan lain sebagainya. Lihat Afzalurrahman, Indeks Al-Qur'an, (Jakarta: PT Bumi Aksara, 2001), 175.

2Mann`al-Qatthan, Mabahits fi Ulum al-Qur`an, (Riyadh: Muassasah al-Risalah, 1976), 124.

${ }^{3}$ Ibnu Katsir, Kisah Para Nabi, (Jakarta: Pustakazzam, 2007), 271-274.

4 Sayyid Qutbh, Tafsir Fi Zhilalil Qur'an, (Jakarta: Gema Insani, 2003), Jilid VI, 301. Lihat juga Kementerian Agama RI, Al-Qur'an dan Tafsirnya, (Jakarta: Lentera Abadi, 2010), Jilid IV, 493. Lihat Buya Hamka, Tafsir Al-Azhar Juz X, (Jakarta: Pustaka Panjimas, 1985), 160. Lihat juga Ibnu Katsir, Lubabul Tafsir Min Ibni Katsir, (Bogor: Pustaka Imam Asy-Syafe i, 2003), Jilid IV, 398. Lihat juga Muhammad Jalaluddin Al-Qasimi, Tafsir Al-Qasimi Mahasin At-Takwil, (Bairut Libanon: Darul Al'Ilmiyah, tt.p), Jilid 6, 144. Lihat Syahabudin Sayyid Muhammad Alwi Baghdadi, Ruhul Ma`ani Fi Tafsir Al-Qur'an Al-Adzim Wa Saba ul Matsaniy, (Bairut Libanon: Darul Al-'Ilmiyah, tt.p), Jilid 6, 362. Lihat Muhammad Ahmad Musthofa Abu Zahrah, Zahratun At-Tafasir, (t.tp, t.th), Jilid VI, 3781. 
konspirasi terhadapmu) Ia berkata pada suatu malam mereka bermufakat berniat jahat terhadap Nabi Muhammad SAW, lalu Allah SWT memperlihatkan kepada nabi-nabinya atas hal itu, maka `Ali bin Abi Thalib tidur pada tempat Rasulullah SAW sedangkan beliau keluar hingga sampai di gua Tsur, sementara orang-orang musyrik pada malam itu menjaga 'Ali mereka menduga bahwa ia adalah Nabi Muhammad SAW. ${ }^{5}$

Pada dewasa ini jika dilihat melalui sudut pandang dengan pendekatan teori konspirasi yang dikembangkan oleh para pengguna (konspirator), melihat begitu urgennya kisah yang Allah SWT tampilkan terhadap kisah dramatisasi tersebut, sehingga peristiwa itu hampir serupa dan terulang di masa Rasulullah SAW. Maka dari itu peneliti ingin mengangkat atau mengkaji bagaimana Kisah Dramatisasi Saudara-saudara Nabi Yusuf as Melalui Pendekatan Teori Konspirasi, serta otak di balik peristiwa yang mengakibatkan Yusuf as berada di dalam sumur.

\section{METODE PENELITIAN}

Adapun metode yang digunakan ialah kualitatif. ${ }^{6}$ Kemudian jenis penelitian yang digunakan dalam penelitian ini adalah lebih menekankan dengan pendekatan kepustakaan, ${ }^{7}$ (library research) penelitian yang didasarkan atas penelusuran literatur-literatur berkaitan dengan masalah yang dibahas. ${ }^{8}$ Teknik pengumpulan merupakan inti dari setiap kegiatan penelitian. Dalam hal pengumpulan data pada pengembangan, data dapat dilakukan membaca literatur-literatur baik yang merupakan sumber data primer maupun sekunder. Setelah membacanya peneliti melakukan verifikasi terhadap bagian-bagian literatur yang dapat dianalisis, verifikasi ini dibutuhkan agar tidak terjadi pelebaran aspek pembahasan dari obyek penelitian. ${ }^{9}$ Pada umumnya, kegiatan analisis data penelitian dilakukan setelah pengumpulan data selesai, di mana data yang terkumpul lalu dianalisa secara deskriptif yakni menggambarkan, 398.

5Ibnu Katsir, Lubābul Tafsir Min Ibni Katsir, (Bogor: Pustaka Imam Asy-Syafe`i, 2003), Jilid IV,

${ }^{6}$ Merupakan metode yang digunakan mengedepankan setiap yang melekat pada sebuat fenomena. Lihat John W. Creswell, Penelitian Kualitatif dan Desain Riset Memilih Di Antara Lima Pendekatan, (Yogyakarta: Pustaka Pelajar, 2005), 108-109.

${ }^{7}$ Dalam kamus bahasa Indonesia kepustakaan adalah daftar kitab yang dipakai sebagai sumber acuan untuk tulisan mengenai suatu bidang tertentu. Lihat Tim Penyususn KBBI, Kamus Bahasa Indonesia Edisi ke-5, (Jakarta: Balai Pustaka 2016), 232. 2010), 23.

${ }^{8}$ Suharsimi Arikunto, Prosedur Penelitian Suatu Pendekatan Praktik, (Jakarta: Rineka Cipta, 2017), 21

Fredi Suhendra: Kisah Dramatisasi Saudara-Saudara Nabi Yusuf... 
menguraikan, dan menyajikan seluruh pembahasan yang ada pada pokok-pokok permasalahan. ${ }^{10}$

\section{HASIL DAN PEMBAHASAN}

\section{Konspirasi Terhadap Nabi Yusuf As}

Sebagaimana dikatakan di dalam Al-Qur`an, mereka saudara-saudara Nabi Yusuf as memulainya dengan menyusun strategi untuk melenyapkan Yusuf as. Allah SWT berfirman QS Yusuf: 9-10

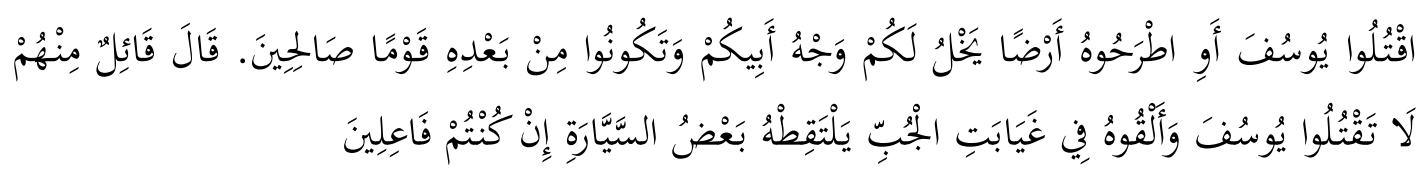

"Bunuhlah Yusuf as atau buanglah dia ke suatu daerah (yang tak dikenal) supaya perhatian ayahmu tertumpah kepadamu saja, dan sesudah itu hendaklah kamu menjadi orang-orang yang baik. Seorang di antara mereka berkata: "Janganlah kamu bunuh Yusuf as, tetapi masukkanlah dia ke dasar sumur supaya dia dipungut oleh beberapa orang musafir, jika kamu hendak berbuat."

Ayat di atas mendeskripsikan langkah awal alur kerja konspirasi yang dilakukan oleh saudara-saudara Nabi Yusuf as terhadap dirinya, di mana di awali

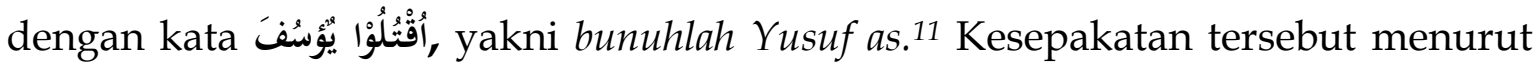
teori konspirasi disinformation, di lakukan secara berkelompok dan ter-organisir secara tersembunyi. ${ }^{12}$ Sasaran utamanya adalah mengubah sikap dan perilaku khalayak untuk mendukung atau menolak suatu isu tertentu. Tujuan konspirasi ini mengubah atau mengaburkan posisi suatu sikap dan perilaku seseorang ke suatu sikap yang lain. Banyak orang menggunakan ini untuk mengulang dukungan, menerima, atau monolak suatu isu tertentu.

10Sugiyono, Metode Penelitian dan Pengembangan Research and Develoment..., hlm. 245. Lihat juga Boy S Sabarguna, Analisis Data Pada Penelitian Kualitatif, (Jakarta: UI-Press, 2008 ), 99.

${ }^{11}$ Kalimat tesebut mengisyaratkan perintah dalam bentuk jama', di mana ditandai dengan kemasukan wau menunjukkan mereka melakukan perintah tersebut lebih dari dua orang Lihat Abu Hasan `Ali bin Hisyam Kailani, Sarhu Al-Kailani, t.tp, t.th, hlm. 11. Lihat juga `Abdul Wahab bin Imaduddib, bin Ibrahim bin, Matan Bina Wal Asas, (Surabaya: Sa`ad bin Nasir Nabhan, t.th), 17.

${ }_{12}^{12}$ Periwtiwa konspirasi yang sempat viral di mana kasus yang menjerat ketua KPK yakni Antasari Azhar. Ia dijebak sebagai otak pembunuhan bos PT. Putra Rajawali Banjaran yang oleh beberapa kalangan diduga penuh dengan aroma konspirasi, ketika ingin mengajukan peninjauan kembali atas kasusnya, Mahkamah Agung menolaknya tanpa disertai alasan kuat. Maka merebak dugaan bahwa mantan jaksa yang tengah getol memberantas korupsi di Indonesia itu sengaja dijebloskan ke penjara oleh jaringan konspirasi yang melibatkan komlomerat hitam pejabat tinggi, bahkan lingkaran dalam istana kepresidenan. Untuk lebih jelas lihat Abhee Antara, Teori Konspirasi Peristiwa, Kasus, Isu Politik Indonesia dan Dunia..., 84. 


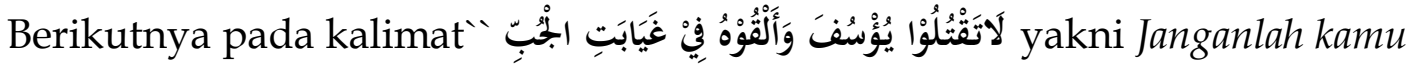
membunuh Yusuf as, tetapi masukkanlah saja dia ke dalam sumur. Kata غَيَابَة ada juga yang membacanya dalam bentuk jamak غَيَبَاتٍ terambil dari akar kata غيب yakni tidak terlihat, maksudnya dasar yang terdalam dari sumur. ${ }^{13}$ Planing setelahnya mereka berdiskusi dan menentukan apakah Yusuf as dibunuh atau membuangnya ke tempat daerah tidak terjamah oleh seseorang.

Akhirnya mereka bersepakat memasukkan Yusuf as ke dalam sumur, ${ }^{14}$ kesepakatan tersebut saudara-saudaranya lakukan selanjutnya ialah membuat koorporasi kepada Ya`kub as agar menyakini perkataan yang mereka sampaikan untuk melancarkan konspirasinya, di mana alur kerjanya dengan menggunakan teknik pendekatan persuasif manipulatif. ${ }^{15}$

\section{Dramatisasi koorporasi Saudara Nabi Yusuf Terhadap Ya`qub As}

Setelah mereka bermufakat memasukkan nabi Yusuf as ke dalam sumur, langka selanjutnya yang ditempuh. Melakukan pendekatan-pendekatan persuasif manipulaif seperti, Allah SWT deskripsikan di dalam QS Yusuf: 11-14

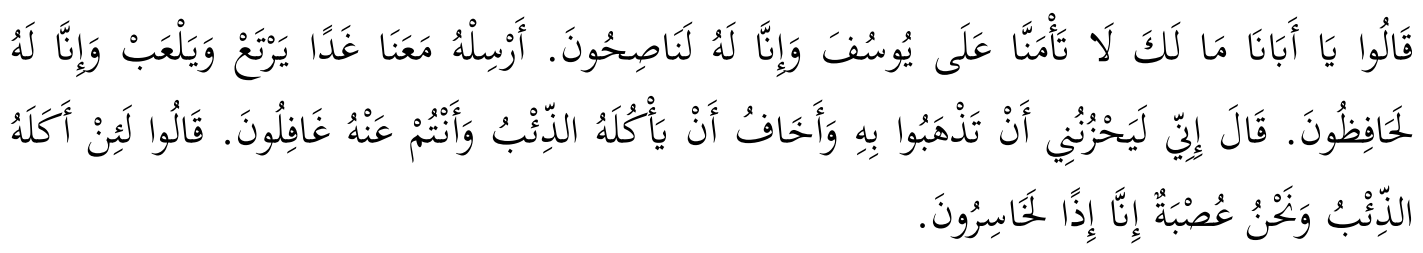

"Mereka berkata: "Wahai ayah kami, apa sebabnya kamu tidak mempercayai kami terhadap Yusuf as. Padahal Sesungguhnya kami adalah orang-orang yang mengingini kebaikan baginya. Biarkanlah dia pergi bersama kami besok pagi, agar dia (dapat) bersenang-senang dan (dapat) bermain-main, dan sesungguhnya kami pasti menjaganya." Berkata Ya'qub as: "Sesungguhnya kepergian kamu bersama Yusuf as amat menyedihkanku dan aku khawatir kalau-kalau dia dimakan serigala, sedang kamu lengah dari padanya. Mereka berkata: "Jika ia benar-benar dimakan

${ }^{13}$ M. Quraish Shihab, Tafsir Al-Misbah..., hlm. 16. Sedangkan pendapat lain mengatakan di dalam sumur tersebut sama sekali tidak ada batu sehingga nabi Yusuf as tidak bisa keluar dari dalam sumur tersebut. Lihat Muhammad Jalaluddin Al-Qasimi, Tafsir Al-Qasimi Mahasin At-Takwil, Bairut Libanon, Darul Al-'Ilmiyah, t.th, Jilid 6 hlm. 156. Akan tetapi menurut pendapat Sa`id Hawiy Sumur tersebut sebagai alat untuk menjauhkan Yusuf as dari ayahnya dan tidak membunuhnya, karena saudara-saudaranya mengetahui bahwa membunuh itu sesuatu yang amat besar dosanya. Lihat Sa id Hawiy, Al-Asasu Fi At-Tafsir, (Mesir: Dārus Salām, t.th), Jilid VI, 2636.

${ }^{14}$ Keadaan di dalam sumur tersebut menyerupai sebuah goa atau seperti sebuah lorong kecil di atasnya air bisa memenuhinya. Apa saja yang masuk di dalamnya akan tenggelam, lenyap dari pandangan mata. Di sini memberikan pandangan atau isyarat bahwa untuk menghendaki keinginan mereka dengan cara mencelakai dari saudaranya sendiri. Lihat Syahabuddin Sayyid Muhammad Alwi Baghdadi, Ruhul Ma`ani Fi Tafsir Al-Qur`an Al-Adzim Wa Saba`ul Matsaniy, (Bairut Libanon: Dārul Al-'Ilmiyah, t.th), Jilid VI, 384.

${ }^{15}$ Abhee Antara, Teori Konspirasi Peristiwa, Kasus, Isu Politik Indonesia, dan Dunia..., 86. 
serigala, sedang kami golongan (yang kuat), Sesungguhnya kami kalau demikian adalah orang-orang yang merugi.

Teknik yang mereka (saudara-saudara Nabi Yusuf as) pakai yakin, dengan pendekatan persuasif, manipulatif, 16 membujuk sang ayah agar mau menuruti keinginannya. Berusaha menciptakan perasaan senang terhadap khalayak/individu supaya merasa menjadi bagian dari komunikasi yang sedang dilaksanakan. ${ }^{17}$ Teknik ini juga menggunakan kata yang baik melukiskan sesuatu agar mendapat dukungan, tanpa menyelidiki ketepatan asosiasi itu, teknik ini digunakan untuk menonjolkan pelaku dengan mengidentifikasi dirinya dengen segala apa yang serba luhur dan agung contoh: Di saat Amerika Serikat merencanakan serangan militer ke Irak. Amerika menyebutnya sebagai suatu misi kemanusiaan untuk membebaskan manusia dari teror senjata pemusnah massal. ${ }^{18}$

Kalimat اَرْبلْلُهُ مَعَنَا menurut Wahbah Al-Zuhayli merupakan mengeksplorasi ke tempat yang dituju yakni, Yusuf as dan saudara-saudaranya pergi pagi-pagi sekali agar bisa bermain di sana dan tugas mereka (saudara-saudaranya) menjaga atau memperhatikannya. Sedangkan يَتَنْعَبْ dan menyenangkan Yusuf as dengan cara memberinya buah-buahan, dan berlomba memanah anak panah. ${ }^{19}$

Retorika atau konspirasi yang mereka gunakan dalam kajian ilmu bayan termasuk jenis majaz yang digunakan tidak pada tempatnya, karena ada keterkaitan serta alasan yang mencegah dari makna terdahulu. ${ }^{20}$ Maksudnya seorang anak tidak begitu pantas berbicara kepada orang tua (Ya 'qub as) dengan membohonginya untuk memuluskan niat jahat mereka terhadap Yusuf as.

Dalam sisi lain dapat juga dikatakan bahwa teknik alur kerja yang mereka pakai menggunakan glittering genarality di mana para konspirator berusaha menghunungkan sesuatu dengan kata yang baik dipakai untuk membuatnya

${ }^{16}$ Dalam kamus bahasa Indonesia mempunyai arti. Bersifat membujuk secara halus, serta dengan teks yang menggunakan alasan-alasan implisit., Lihat Tim Pustaka Phoenix, Kamus Besar Bahasa Indonesia, (Jakarta: Media Pustaka Phoenix, t.th), 212

${ }^{17}$ Alip Yog Kunandar, Memahami Propaganda Metode, Praktik, dan Analisis..., 24

${ }^{18}$ Berdasarkan keterangan tentara veteran Amerika Serikat bahwa misi kemanusia di sana merupakan sebuah konspirasi. Ia menyadari bahwa tidak pernah ada senjata pemusnah massal, dan batapa susahnya kami mencari-cari teroris walaupun bahkan telah mengerahkan semua kekuatan meliter, ia juga menambahkan bahwa patriotisme saya telah dieksploitasi untuk kepentingan politik AS belaka dan pengorbanan kami jelas menjadi sia-sia serta di khianati. Lihat https://m.eramuslim.com di upload pada tanggal 04-04-2019.

${ }^{19}$ Wahbah Al-Zuhayli, Al-Tafsir Al-Munir Fi Al-'Aqidah Wa Al-Shari ah Wa Al-Manhaj, (Beirut Libanon, Darul Al-Fikr Al-Mu`asir, 2000), Jilid VIII, 221.

${ }^{20}$ Bakri Syaikh Amin, Al-Balaghah Al-`Arabiyah fi Tsaubina al-Jadid al-Bayan, (Bairut: Dar 'Ilm li al-Malayin, 1995), Juz II, 18. Lihat juga Abdurrahman Al-Ahdhori, Terjemah Jauharul Maknun Ilmu Balaghah, (Surabaya: Mutiara Ilmu, 1995), 100. 
menerima dan menyetujuinya. ${ }^{21}$ Pengungkapan dengan kalimat-kalimat dan redaksinya ini menggambarkan bagaimana saudaranya tersebut mencurahkan segenap kemampuannya agar dapat mempengaruhi hati Ya`kub as.

Berikutnya mendengar penjelasan dari mereka, ayahnya memberikan argumentasi. Berkata Ya'qub as: "Sesungguhnya kepergian kamu bersama Yusuf as amat menyedihkanku dan aku khawatir kalau-kalau dia dimakan serigala, sedang kamu lengah dari padanya. Kalimat yang menunjukkan ذِيْْبْ (serigala) manifestasikan ada mengartikan yaitu saudara-saudara Nabi Yusuf as yang cemburu kepadanya. ${ }^{22}$

Dari sahabat Ibnu Kaab Ibnu Malik Al-Anshary dari ayahnya berkata "Rasulullah SAW beersabda: Tidaklah dua serigala dilepas pada kambing lebih merusak dibandingkan ambisi seseorang pada harta dan kedudukan yang akan merusak agamanya. ${ }^{23}$ Hadits di samping mendeskripsikan bahwa betapa sangat detail konotasi Rasulullah SAW dari sebuah keserakahan manusia, gambaran kerusakan yang divisualisasikan dalam bentuk dua serigala yang lapar siap dilepaskan pada sekawanan domba. ${ }^{24}$

Selanjutnya, kalimat yang Allah SWT abadikan dalam Al-Qur`an, peristiwa

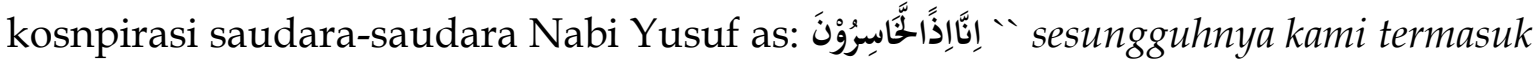
orang-orang yang merugi “. Kata di samping mendeskripsikan, sebagai penguat dari ayat sebelumnya karena terdapat huruf إِّ taukid,25 mereka (saudara-saudara Nabi Yusuf as) mempertegas atas sanggahan ayahnya bahwa mampu menjaga Yusuf as karena merupakan bagian dari darah daging kami. Penegasan tersebut sekaligus merekontruksi untuk memuluskan niat jahat mereka terhadap Yusuf as, dengan harapan agar Ya`qub as lebih percaya setelah saudara-saudara melontarkan perkataan tersebut. Demikian jahatnya mereka sampai-sampai berkata dusta terhadap ayahnya sendiri.

Stimulus/rencana yang mereka terapkan terhadap Ya`qub as akhirnya berhasil, tiba saatnya di mana pada ke-esokan harinya Yusuf as di bawah pergi

21Untuk lebih jelas lihat Abhee Antara, Teori Konspirasi Peristiwa, Kasus, Isu Politik Indonesia dan Dunia..., 23. Lihat juga Alip Yog Kunandar, Memahami Propaganda Metode, Praktik, dan Analisis..., 105.

${ }^{22}$ M. Quraish Shihab, Tafsir Al-Misbah, (Jakarta: Lentera Hati, 2002), Jilid IV, 21.

23Tirmidzi, Sunan At-Tirmidzi Mā Jā Fi Akhadil Mali Fi Haqqihi, (t.tp, t.th), Juz VIII, 381.

${ }^{24}$ Dalam acara program wild life menggambarkan serigala memangsa buruannya, mencekram, menerkam, menggigit, dan merobek saling tarik antara satu serigala dengan yang lainnya menjadi hal biasa, sebab masing-masing ingin mendapat makanan yang paling banyak.

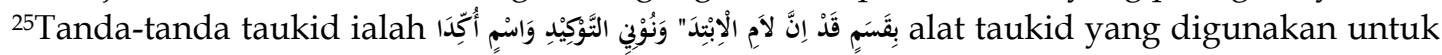
kalam khabar ialah: Qasam, Inna, Lam ibtida', dan dua macam nun taukid (tsaqilah dan khofifah) dan jumlah ismiyah. Lihat Lihat juga Abdurrahman Al-Ahdhori, Terjemah Jauharul Maknun Ilmu Balaghah..., 24-25. 
ke suatu tempat yang jauh di padang pasir. ${ }^{26}$ Kemudian saudaranya melemparkannya ke dalam sumur, ${ }^{27}$ Allah SWT berfirman QS Yusuf: 15

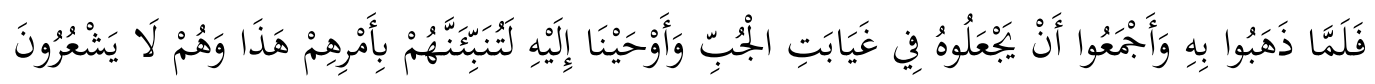

"Maka tatkala mereka membawanya dan sepakat memasukkannya ke dasar sumur (lalu mereka masukkan dia), dan (di waktu dia sudah dalam sumur) kami wahyukan kepada Yusuf As: "Sesungguhnya kamu akan menceritakan kepada mereka perbuatan mereka ini, sedang mereka tiada ingat lagi."

Menurut Johan Galtung kekerasan personal terjadi bila manusia dipengaruhi sedemikian rupa, sehingga realisasi jasmani dan mental aktualnya berada di bawah realisasi potensialnya, beliau juga menambahkan dimensi yang terealisasikan akibat dari kekerasan tersebut. Terjadinya kekerasan fisik maupun psikologis, dalam fisik tubuh menusia disakiti secara jasmani bahkan sampai membunuh. Sedangkan kekerasan psikologis tekanan yang dimaksudkan meredusir kemampuan mental dan otak. ${ }^{28}$

Kasus yang menimpah Yusuf as merupakan kekerasan personal dilakukan oleh sudara-saudaranya, dengan memasukkannya ke dalam sumur. ${ }^{29}$ Kata yang dipakai Al-Qur`an pada padanan غَيَابَة, ada juga yang membacanya dalam bentuk jamak غَيَبَاتٍ terambil dari akar kata غيب yakni tidak terlihat, maksudnya dasar yang terdalam dari sumur, menurut Sa id Hawiy sumur tersebut sebagai alat untuk menjauhkan Yusuf as dari ayahnya dan tidak membunuhnya, karena saudara-saudaranya mengetahui bahwa membunuh itu sesuatu yang amat besar dosanya. ${ }^{30}$ Ditinjau dalam pendekatan teori konspirasi ayat tersebut, pemaknaan kata "sumur" dapat diartikan sebagai alat untuk menjauhkan khalayak (korban) yang dipraktikkan oleh konspirator, mengingat para pengguna teori konspirasi

${ }^{26}$ Wahbah Al-Zuhayli, Al-Tafsir Al-Munir Fi Al-`Aqidah Wa Al-Shari ah Wa Al-Manhaj..., 220.

${ }^{27}$ Dalam tafsir Ibnu Katsir keadaan Nabi Yusuf as di dalam sumur tersebut, mereka membawanya ke sumur yang telah disepakati untuk membuangnya, dengan cara mengikatnya denga tali dan timbal. Pada saat yang sama ia meminta tolong kepada salah seorang di antara mereka, lantas ia menjawab dengan tamparan dan makian. Bila berusaha bertahan di bibir sumur, mereka pukuli tangannya lalu, mereka potong talinya di tengah-tengah. Sehingga ia jatuh ke dalam air dan tenggelam, lalu ia merangkak ke atas batu di tengah sumur yang disebut dengan Raghufah dan berdiri di atasnya. Lihat Ibnu Katsir, Lubābul Tafsir Min Ibni Katsir..., 391.

28Thomas Santoso, Kekuasaan dan Kekerasan Masyarakat, Kebudayaan, dan Politik, Journal UINAIR, 2001, Vol. IV, 92-94.

${ }^{29}$ Menurut pendapat Ibnu Katsir mereka membawanya ke sumur yang telah disepakati untuk membuangnya, dengan cara mengikatnya denga tali dan timbal. Pada saat yang sama ia meminta tolong kepada salah seorang di antara mereka, lantas ia menjawab dengan tamparan dan makian. Bila berusaha bertahan di bibir sumur, mereka pukuli tangannya lalu, mereka potong talinya di tengah-tengah. Sehingga ia jatuh ke dalam air dan tenggelam. Lihat Ibnu Katsir, Lubābul Tafsir Min Ibni Katsir..., 406

30Sa id Hawiy, Al-Asasu Fi At-Tafsir, (Mesir: Darus Salam, t.th), Jilid VI, 2636.

Fredi Suhendra: Kisah Dramatisasi Saudara-Saudara Nabi Yusuf... 
adalah pemerintah dan organisasi. ${ }^{31}$ Maka alur kerja yang dipakai oleh mereka untuk menghilangkan jejak dengan cara memasukkannya di dalam sumur, karena hal ini kontras saat situasi dan kondisi tanah di sana. ${ }^{32}$

\section{Konspirasi Disinformation}

Setelah berhasil melaksanakan niat mereka dengan menggunakan pola dan taktik yang terencana matang, selanjutnya alor keja dipraktikkan oleh saudarasaudara nabi Yusuf as, menurut teori konspirasi disinformation, di mana subjek mengaburkan atau menghapus sejumlah informasi dari catatan-catatan umum yang bertujuan menciptakan seolah-olah ada catatan palsu tentang peristiwa atau tindakan seseorang. Cara melakukannya, dengan menyebarkan informasi palsu, tidak lengkap, dan informasi yang menyesatkan kepada individu dan kelompok atau negara menjadi target, kemudian informasi yang disebarkan telah dirancang sedemikian rupa. ${ }^{33}$ Allah SWT berfirman QS Yusuf: 16-1:8

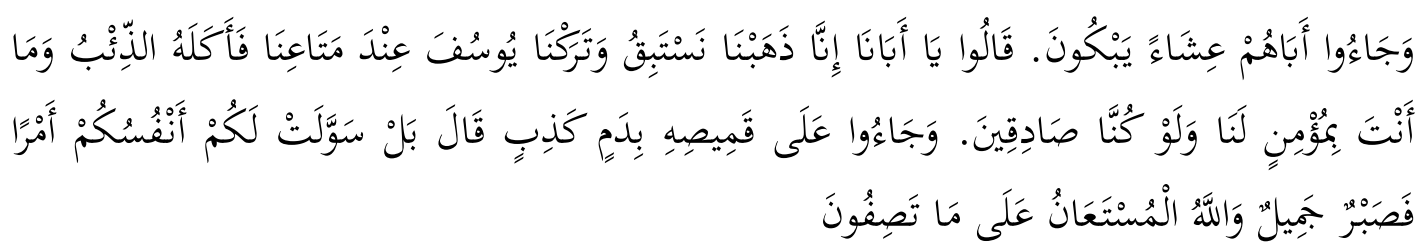

"Kemudian mereka datang kepada ayah mereka di sore hari sambil menangis. Mereka berkata: "Wahai ayah kami, sesungguhnya kami pergi berlomba-lomba dan kami tinggalkan Yusuf as di dekat barang-barang kami, lalu dia dimakan serigala; dan kamu sekali-kali tidak akan percaya kepada kami, sekalipun kami adalah orangorang yang benar. Mereka datang membawa baju gamisnya (yang berlumuran) dengan darah palsu. Ya'qub as berkata: "Sebenarnya dirimu sendirilah yang memandang baik perbuatan (yang buruk) itu; Maka kesabaran yang baik Itulah (kesabaranku). dan Allah SWT sajalah yang dimohon pertolongan-Nya terhadap apa yang kamu ceritakan.

Berita hoaks yang mereka sampaikan kepada Ya`qub as, di mana dramatisasi lakon sandiwara diterapkannya mempunyai tiga alur kerja. Pertama, pada kalimat وَجَايُوْ أَبَاهُمْ عِشَاءُ يَبْكُوْنَ Mereka datang kepada ayah mereka di malam hari sambil menangis. Alur kerja menurut tinjauan pendekatan teori konspirasi, pada

${ }^{31}$ Dalam organisasi politik misalnya, para kandidat berusaha untuk membentuk pendapat umum (publik opinion) dari para pemilih. Untuk keberhasilan pembentukan, maka banyak organisasi mempekerjakan orang-orang yang disebut lobbyists (tim lobi). Mereka inilah yang memersuasi para pemimpin masyarakat (pablic leader) agar menarik anggota mesyarakatnya memilih para kandidat tersebut. Tim lobi bekerja untuk menjinakkan kelompok-kelompok penekan, misalnya saja dalam isu-isu, berita hoaks, hak asasi manusia, dan lain sebagainya. Lihat Alip Yog Kunandar, Memahami Propaganda Metode, Praktik, dan Analisis..., 100-101.

32Syauqi Abu Khalil, Jejak Para Nabi, (Jakarta: Batara Offset, 2005), 85.

${ }^{33}$ Abhee Antara Teori Konspirasi, (Jakarta Selatan: Media Kita, 2013), 22-23.

Fredi Suhendra: Kisah Dramatisasi Saudara-Saudara Nabi Yusuf... 
ayat di atas merupakan bentuk manifulasi dari kejahatan mereka dengan berlakon, yakni menangis di hadapan ayahnya bahwa telah terjadi sesuatu yang buruk terhadap Nabi Yusuf as. Biasanya teknik ini dipakai oleh pelaku konspirasi (konspirator) untuk mempengaruhi/ menciptakan daya tarik emosi atau stereotip. Menutupi kejahatan mereka dengan cara menangis, berkamuflase agar ayahnya percaya akan berita yang disampaikannya.

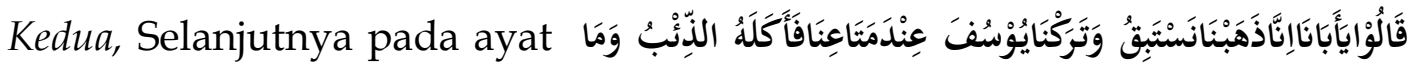

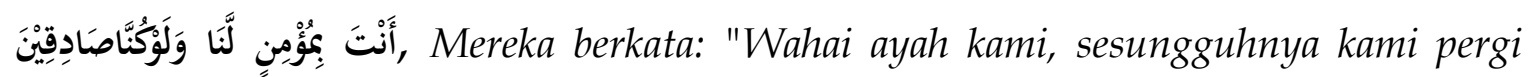
berlomba-lomba dan kami tinggalkan Yusuf di dekat barang-barang kami, lalu dia dimakan serigala; dan kamu sekali-kali tidak akan percaya kepada kami, Sekalipun kami adalah orang-orang yang benar. Kelanjutan dari ayat yang sebelumnya menceritakan kemampuan mereka dalam berakting, pada ayat ini merupakan kelanjutannya. Di mana dengan pendekatan Card Stacking konspirator (saudara-saudaranya) beragumentasi dengan menyampaikan sebuah gagasan/pernyataan-pernyatan yang logis maupun tidak logis. Card Stacking ini juga tidak lain mempunyai tujuan, yakni untuk menjatuhkan mental lawan atau sebaliknya, meraih simpati bahwa telah menjadi korban sebuah kejahatan. Asumsi/pendapat ini diperkuat

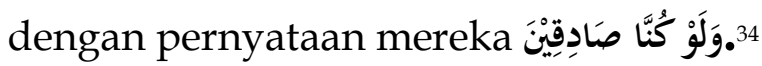

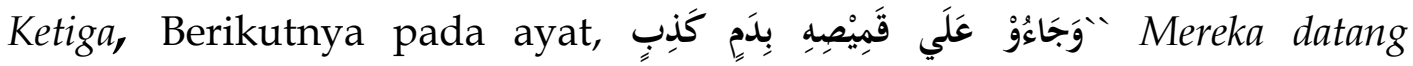
membawa baju gamisnya (yang bermuluran darah) dengan darah palsu. Pernyataan saudara-saudara nabi Yusuf as kepada ayahnya, semakin menjadi-jadi, untuk menyakinkan Ya`qub as bahwa Yusuf as di makan oleh serigala dengan membawa baju gamisnya yang berlumuran darah. Alur kerja yang mereka terapkan menurut teori konspirasi disinformation, menggunakan taktik atau teknik Rationalization (rasionalisasi) bisa juga dikatakan making excuses merupakan teknik memaparkan alasan-alasan yang rasional tentang suatu, isu, gagasan, atau tindakan tertentu. Tujuan pernyataan ini untuk merasionalkan isu, gagasan dan tindakan yang dilakukan oleh khalayak dalam hal ini pelaku konspirasi (konspirator). Kemudian secara umum tekni ini ada beberapa bentuk di antaranya: a.) Menutupi kekecewaan. b.) Membenarkan tindakan atau menutupi kadar kesalahan. c.) menanggapi tuduhan. ${ }^{35}$ Kata yang mereka gunakan untuk menutupi perbuatannya ialah قَمْيْصِهِ بِدَدِم baju yang berlumuran darah, sebagai alat

${ }^{34}$ Kata yang dipakai mereka untuk menyembunyikan kejahatannya ialah صادقون. Dalam lisanun `Arabi, biasanya dipakai untuk memantapkan/mempercayai sebuah pertemuan yang telah disepakati oleh kedua belah pihak atau lebih. Lihat Jamaluddin Muhammad Bin Makram Bin Mandzur, Lisanun Al-`Arabi, (Libanon: Dārul Fikr 1990), Jilid VI, 95.

${ }^{35}$ Alip Yog Kunandar, Memahami Propaganda Metode, Praktik, dan Analisis..., 159. 
menutupi kejahatan mereka, dengan bukti tersebut diharapkan Ya`qub as percaya akan perkataan-perkataannya.

\section{PENUTUP}

Praktik dramatisasi konspirasi yang diterapkan saudara-saudara Nabi Yusuf as merupakan proses dramatisasi alur kerja konspirasi yang dipraktikkan oleh saudara-saudara Nabi Yusuf as sangat terstruktur. Mereka memulainya dengan berdiskusi, bermufakat menyusun rekonstruksi strategi secara berkelompok dan ter-organisir, kemudian melakukan koorporasi kepada ayahnya Ya`qub as melalui pendekatan persuasif, berkamuflase sehingga menciptakan daya tarik emosi, hingga klimaksnya Nabi Yusuf as berada di dalam sumur. Di mana yang mengusulkan agar Yusuf as dimasukkan ke dalam sumur yakni, Ruben merupakan saudara tirinya sendiri.

\section{DAFTAR PUSTAKA}

Abu Zayd, Hashar Hamid. Al-Qur'an Hermeneutik dan Kekuasaan, Bandung: Korpus, 2003.

Afzalurrahman. Indeks Al-Qur'an. Jakarta: PT Bumi Aksara, 2001.

Agama, Kementerian. Al-Qur'an dan Tafsrinya. Jakarta: Sinergi Pustaka Indonesia, 2010.

Al-Qur'an dan Terjemahannya. Jakarta: Sinergi Pustaka Indonesia. 2012.

Ahdhori, Abdurrahman. Terjemah Jauharul Maknun. Surabaya: Mutiara Ilmu, 1995.

Ali Hasan Abi, Naisaburi Ahmad Wasidi. Al-Wasith Tafsir Al-Qur'an. Libanon: Dārul Kutub Al-Ulumiah, t.th.

Ali, Nadwi, Abdul, Hasan. Islam dan Dunia. Bandung: Angkasa, 1997.

Ali Shabuni, Muhammad, Shafwatu At-Tafāsir. Libanon, Bairut Fikr, t.th.

Alkitab, Tim Penyusun. Alkitab Deuterokanonika, Jakarta, Lembaga Alkitab Indonesia, 2004.

Alwasilah. Pokok Penelitian Kualitatif Dasar-dasar Merancang dan Melakukan Penelitian Kualitatif, Jakarta, Kiblat Buku Utama, 2003.

Almunadi. Ulumul Qur'an 1, Palembang, Grafika Telindo Press, 2012.

Anwar, Abu. Ulumul Qur'an Sebuah pengantar. PekanBaru: Amzah, 2002.

Amal, Syamsu, Rizal. Tafsir Kontekstual Al-Qur'an. Bandung: Mizan, 1990.

Arikunto, Suharsimi. Prosedur Penelitian Suatu Pendekatan Praktek, Jakarta, Renika Cipta, 2010.

Aris, Fu`ad. Pelajaran Hidup Surah Yusuf. Jakarta: Mizan, 2019.

Arkoun, Muhammad. ethinking Islam, Diterjemahkan Oleh Yudian, Asmin. Yogyakarta: Pustaka Pelajar, 1996. 
48 | Semiotika-Q, Vol. 1, No. 1, Juni 2021

Bahreisj, Hussein, Hadits Shahih Al-Jamius Shahih Bukhari Muslim, Karya Utama, Surabaya, t.th.

Bergant Dianne, Karfis Robert. Tafsir Alkitab Perjanjian Lama. Yogyakarta: Kanisius, 2002.

Corbin Juliet, Strauss Anselm. Dasar-Dasar Penelitian Kualitatif Tatalangkah dan Teknik-Teknik Teorisasi Data. Yogyakarta: Pustaka Pelajar, 2017.

Creswell, John. (2015) Penelitian Kualitatif dan Desain Riset Memilih di Antara Lima Pendekatan, Yogyakarta, Pustaka Pelajar.

Darmawan, Dadang, Analisa Kisah Nabi Yusuf Dalam Al-Qur'an Dengan Pendekatan Hermeneutika, Jurnal Al-Bayan, Vol IV.

Dzahari, Husain, Muhammad. (1996), Penyimpangan-penyimpangan Dalam Penafsiran Al-Qur`an, Jakarta, Raja Grafindo Persada.

Faiz, Fakhruddin. Hermeneutika Qur`ani. Yogyakarta: Qalam, 2002.

Fu’ad Wahab, Muhsin Wahab. Pokok-pokok Ilmu Balaghah, Bandung, Angkasa, 1982.

Galayini, Musthofa. Jami Durus Arabiyyah, Libanon, Dārul Kutub Al-'lmiyyah, 2009. 